\title{
Syringomyelia in Pregnancy- Is Caesarean Section The Best Option For Delivery? - A Case Report
}

\author{
Hakim Ba, Roszaman Ra, Nor Ziana AW ${ }^{a}$, Che Anuar $C^{b}$ and Jefri $A^{c}$ \\ a Department of Obstetrics and Gynaecology, Kulliyah of Medicine, International \\ Islamic University Malaysia. \\ b Department of Obstetrics and Gynaecology and \\ c Department of Neurosciences, School of Medical Sciences, University Sains \\ Malaysia.
}

ABSTRACT:

Syringomyelia is a rare neurological disease, which is characterized by the formation of a cyst in the spinal cord. The aetiology of the disease still remains controversial. The damage to the spinal cord results in headache, weakness, stiffness and numbness on both lower and upper limbs. Only few a cases of syringomyelia in pregnancy have been reported thus far. As such, there is no standard management of intrapartum care. 1 We present a case of symptomatic syringomyelia in pregnancy, its management and literature review. The mode of delivery with risks for vaginal route is discussed.

KEY WORDS: Syringomyelia, Pregnancy, Caesarean Section.

\section{CASE PRESENTATION}

The patient was a 32year old Primigravida at 38 weeks +4 days period of amenorrhoea (POA). She was initially admitted to the surgical ward and was later transferred out to the antenatal ward for delivery; she had a history of right upper limb numbness for the past 14 years, followed weakness for the last 3 years. She also noticed left lower limb numbness for the last 3 years followed by left upper limb numbness for the last 3 months prior to admission.

The numbness started distally in both in upper and lower limbs which progressed proximally. There was also an associated dull aching pain of the affected limbs. From period of amenorrhoea of 26 weeks, she experienced a progressive weakness of her right upper limb. However this did not prevent her from doing her house chores properly. She denied any history of trauma. There was no change in bladder or bowel habit, nor was there any change in voice or dysphasia.

She did her antenatal booking at 11 weeks POA. Her Venereal Disease Research Laboratory test (VDRL) was non reactive and she had an uneventful follow up. She was diagnosed to have syringomyelia since early adulthood and was on regular neurological follow up

Corresponding author;

Dr. Hakeem Gharib Bilal

Department of Obstetrics \& Gynaecology

Kulliyyah of Medicine,

International Islamic University Malaysia

email: hakimbilal@iiu.edu.my but she was not keen for any surgical intervention. There was no history of similar disease in the family.

Physical examination revealed an alert comfortable lady who was not anaemic, her blood Pressure was $120 / 80 \mathrm{mmHg}$, with a pulse rate $80 / \mathrm{min}$. On abdominal examination she has a term size gravid uterus with cephalic presentation and 3/5 palpable head per abdomen Fetal heart sound was present. Trans-abdominal ultrasound scan comfirmed a singleton pregnancy, cephalic presentation with amniotic fluid index of 9.2 .The placenta was in the anterior upper segment with estimated baby weight of $2.8 \mathrm{~kg}$.

The respiratory and cardiovascular systems were normal. There was no spinal tenderness. Neurological examination prior to delivery revealed normal cranial nerves with reduced tone and power. The sensation of her right limb dermatome was decreased extending from C2 - T2. There was no abnormal gait noted and her anal tone was normal.

After a discussion involving obstetricians, neurosurgeons and anaesthetists it was decided that the patient should be delivered electively by Caesarean by general anaesthesia even though vaginal delivery was not contraindicated. A normal baby boy weighing $2.9 \mathrm{~kg}$ was delivered. Patient refused surgical management of her syringomyelia despite explanation

\section{DISCUSSION}

Syringomyelia is a rare neurological condition which is characterized by the formation of the cyst (syrinx) within the spinal cord. It has a prevalance of 8.4 per 100000 , and affects equally both men and women. ${ }^{2}$ The symptoms usually begin between the age of 25 and 40 yrs. 
The damage in the spinal cord results in pressure symptoms such as pain, weakness of the arms and legs, paroxysmal headaches and loss of hand sensation. The symptoms of the disease usually develop slowly. However, a sudden onset with coughing or straining may occur.

The pathophysiology of syringomyelia has been the subject of controversy. However it seemed that the underlying mechanism is an obstruction in the normal flow of the CSF which then is redirected to the spinal cord itself resulting in the syrinx formation. ${ }^{3}$ There is strong evidence that traumatic birth may play a role. $^{1}$

Pregnancy does not adversely affect syringomyelia nor does the syringomyelia has direct effect on the pregnancy outcomes, although a small for gestational age fetus diagnosed at 28 weeks gestation had been reported. ${ }^{4}$

The data concerning delivery are scanty, although vaginal delivery is not contraindicated. However strict avoidance of straining during the second stage is recommended in case of vaginal delivery. In this case it was decided that elective Caesarean section should be done so as to avoid any possibility of excessive straining during the course of labour which may increase intracranial pressure and damage the spinal cord even further.

General anaesthesia had been used in almost all the reported cases, although epidural anaesthesia was once used. ${ }^{5}$ Epidural anaesthesia is not contraindicated but there is the theoretical risk of injuring the spinal cord/cyst which maybe deformed due to the pressure of the cyst within the spinal cord.

Based on the few reported cases with successive general anaethesia, it is presumed to be a safer choice for a caesarean section in a patient with syringomyelia in pregnancy. ${ }^{2}$ However certain precautions need to be taken to avoid increased in intracranial pressure especially during intubation. ${ }^{6}$

\section{REFERRENCE;}

1. William D. Difficult labour as a cause of com municating syringomyelia. Lancet 1977; 2:51-3

2. Roelofse JA, Shipton EA, Nell AC. Anaesthesia for Caesarean section in a patient with syringomyelia. S Afr Med J 1984; 65:736-7

3. Philips TW, Kindt GW. Syringoperitoneal shunt for syringomyelia: A preliminary report. Surg Neurol 1981; 16:462-6

4. Williams B. Current concepts of syringomyelia. Br J Hosp Med 1970; 331:42

5. Nel MR, Robson V, Robson PN. Extradural anaesthesia for caesarean section in a patient with syringomyelia and Chiary type 1 anomaly. Br J Anaesth 1998; 80:512- 5
6. Muyarama K, Mamiya K, Nozaki K. Caesarean section in a patient with syringomyelia . Can J Anaesth 2001; 48:474 - 7 